\title{
THE HISTORY OF THE THERAPEUTIC USE OF CRUDE PENICILLIN
}

\author{
by \\ MILTON WAINWRIGHT*
}

\section{INTRODUCTION}

The antibacterial properties of culture filtrates of Penicillium notatum were discovered in 1928 by Alexander Fleming, ${ }^{1}$ but the realization of penicillin's full therapeutic potential had to await the contributions of Florey and Chain some twelve years later. ${ }^{2}$ Although early samples of the penicillin salts produced at Oxford were remarkably potent, they were not very pure, ${ }^{3}$ and difficulties with large-scale production meant that even these partially purified products were not initially widely available. This led a number of workers to re-examine the therapeutic properties of crude penicillin filtrates. Since their aim was to produce large amounts of crude filtrate for direct use on patients, complex purification procedures were purposely avoided. In this way, it was hoped that crude penicillin might be produced and used in hospitals, or even by general practitioners; as a result the crude product become known as "home-made penicillin". ${ }^{4}$ These culture filtrates were quite distinct from the partially purified penicillin salts produced by the Oxford workers and are referred to in this essay as crude penicillin.

Essentially, three methods were developed for the topical application of crude penicillin. These were (1) use of liquid filtrates which were usually applied using lint or other absorbent material; (2) the use of dressings inoculated with $P$. notatum often in conjunction with liquid filtrates; and (3) the application of crude penicillin in agar, the so-called pen-agar method. In addition, crude filtrates were also occasionally administered by injection.

A number of remarkable cures were achieved using crude penicillin, but fears concerning its uncontrolled production and purity eventually limited its use. At the same time, however, the partially purified product was becoming more widely available, making the use of crude filtration obsolete. As a result, the relatively large-scale production and use of crude penicillin covered only a short period from

\footnotetext{
* Milton Wainwright, BSc, PhD, Lecturer in Microbiology, Department of Microbiology, University of Sheffield, Sheffield S10 2TN.

${ }^{1}$ A. Fleming, 'On the antibacterial action of cultures of a Penicillium with special reference to their use in the isolation of B. influenzae', Br. J. exper. Path., 1929, 10: 226-236.

${ }^{2}$ E. Chain, H. W. Florey, A. D. Gardner, N. G. Heatley, M. A. Jennings, J. Orr-Ewing, and A. G. Sanders, 'Penicillin as a chemotherapeutic agent', Lancet, 1940, ii: 226-228.

3 D. Masters, Miracle drug, London, Eyre \& Spottiswoode, 1946, p. 102.

4 A. J. Hobson and L. D. Galloway, 'Home-made penicilin', Lancet, 1944, i: 230-231.
} 


\title{
M. Wainwright
}

about 1942 to 1945 . This paper will discuss the development of the use of crude penicillin from Fleming's discovery to its eventual demise. Brief reference will also be made to claims that penicillin was discovered and used prior to Fleming's discovery.

Some Studies on Microbial Antagonism which Pre-Date Fleming's Discovery Although Fleming is rightly credited with the discovery of penicillin, some historians have viewed Victorian work on microbial antagonism ${ }^{5.6}$ as independent discoveries of the antibiotic. Studies by Burdon Sanderson, Lister, Huxley, Tyndall, and William Roberts ${ }^{7}$ have been particularly well examined for evidence to show that the penicillin phenomenon was observed prior to 1928. The physicist and mathematician John Tyndall made observations on microbial antagonism while attempting to disprove the theory of spontaneous generation. ${ }^{8} \mathrm{He}$ noted that bacteria growing in vegetable or meat extracts were sometimes killed when the extracts become contaminated with certain species of fungi, notably Penicillium. In a letter to Huxley, ${ }^{9}$ he accounted for this phenomenon by suggesting that fungi, by growing on the surface of the extract, prevented oxygen from reaching the bacteria. Huxley, however, was not impressed by this explanation because it was obvious that the bacteria died even if the fungus grew over only part of the surface of the extract, when oxygen could not be excluded completely. It seems that Tyndall viewed the antagonism between the Penicillium and bacteria as a Darwinian-style struggle for existence. ${ }^{10}$ Like other Victorian scientists who observed microbial antagonism, he failed to appreciate that fungi might produce a substance inhibitory to bacterial growth. As a result, he never used his extracts on bacterial infections. It has, however, been suggested that as early as 1877 Lister cured a patient by using similar culture filtrates produced by Penicillium glaucum. ${ }^{11}$ The following quotation by Gratia $^{12}$ also shows that extracts of Penicillium glaucum (which he termed mycolysat) were given to a Dr K. Jaumain and used on patients in 1927.

\begin{abstract}
A poor patient who during three years had suffered from furuncles, in spite of all treatments, was sent to us in despair. Jaumain did not hesitate to continue the treatment by a series of injections of the mycolysat. The result was remarkable. Not only was the recovery rapid, but it is now three years that [sic] this recovery continues without the slightest relapse. Since that time we have given the mycolysat to a very large number of cases. It is the most effective treatment even of the most resistant types of staphylococcic diseases.
\end{abstract}

Any assessment of the validity of these claims for pre-Fleming discoveries of penicillin is complicated by the inadequate state of the science of fungal taxonomy during the

${ }^{5}$ D. Zuck, 'Who discovered penicillin?', Wld Med., 1977, 12: 60-65. (See also correspondence, ibid., 11: 14 and 12: 14.)

$6 \mathrm{~J}$. Friday, 'A microscopic incident in a monumental struggle: Huxley and antibiosis in 1875 ', Br. J. Hist. Sci., 1974, 7: 61-71.

${ }^{7}$ W. Roberts, 'Studies on biogenesis', Phil. Trans R. Soc. Lond., 1874, 164: 457-477.

$8 \mathrm{~J}$. Tyndall, 'The optical deportment of the atmosphere in relation to the phenomenon of purification and infection', ibid., 1876, 166: 27-34.

${ }^{9}$ Zuck, op. cit., note 5 above.

$10 \mathrm{~J}$. Tyndall, 'On the optical deportments of the atmosphere in reference to the phenomenon of purification and infection', Proc. $R$. Soc. Lond., 1875-76, 24: 171-183.

${ }_{11}$ W. Fraser-Moodie, 'Struggle against infection', Proc. R. Soc. Med., 1971, 64: 87-94.

$12 \mathrm{~J}$. T. Peters, 'The first discovery of penicillin and of its application in therapy', Acta Medica Scand.. 1946, 126: $60-64$. 
Victorian period ${ }^{13}$ and by the fact that most of the scientists who made the observation had little, if any, knowledge of mycology. These workers may therefore have referred to any fungus as a Penicillium. Even the specific reference to $P$. glaucum only adds to the confusion, since this term was used at that time to describe any green Penicillium species. ${ }^{14}$ These workers may have isolated $P$. notatum or another penicillium-producing member of the $P$. chrysogenum series; it is more likely, however, that their observations refer to any one of the numerous green Penicillium species, or possibly even just any green fungus. So while it is clear that these Victorian scientists observed antagonism between fungi and bacteria, we have no way of knowing whether they observed the penicillin effect sensu stricto.

\section{The First Authenticated Cure Using Crude Penicillin}

Fleming appears to have made a number of largely unsuccessful attempts to demonstrate the therapeutic value of crude penicillin. ${ }^{15}$ In some of this work he collaborated with the eminent surgeon, Arthur Dickson Wright, who was at St Mary's Hospital in London and was a close personal friend of Fleming. ${ }^{16.17}$ He made the following reference to their collaboration in $1945 .{ }^{18}$ "I was interested in penicillin because in 1928 Professor Fleming gave me some to use on cases. It was a yellow fluid in a big test tube, a filtered medium from penicillin [sic] cultures, and seemed to work satisfactorily."

It is often assumed that Fleming's failure to demonstrate the therapeutic value of penicillin resulted from his inability to communicate his enthusiasm to surgeons. ${ }^{19}$ This is unlikely to have been the case as far as Dickson Wright was concerned. On the other hand, Dickson Wright and other surgeons may not have had suitable patients ready when supplies of crude penicillin were available. ${ }^{20}$ Fleming did, however, achieve at least one effective clinical success with crude penicillin when, in 1932, he cured $\mathrm{Dr}$ K. Rogers, who had contracted pneumonococcal conjunctivitis. However, the first authenticated cure using crude penicillin was achieved not by Fleming, but by one of his students, Cecil George Paine, while working in Sheffield. Clinical records of some of Paine's work have recently come to light and they show that as early as 1930, with the help of A. B. Nutt, he used crude penicillin to cure ophthalmia neonatorum in babies. ${ }^{21}$

Paine's work was the last occasion, prior to Florey and Chain's involvement, on which the therapeutic potential of crude penicillin was looked at. Fleming continued to use penicillin in the laboratory, and in America, Reid (who had worked on penicillin during 1930-31 and published his findings in 1935) extended Fleming's laboratory investigations of penicillin, but did not attempt any therapeutic studies. ${ }^{22}$ By the end of the 1930s, however, renewed interest was being shown in microbial antagonism and the

13 J. I. Pitt, The genus Penicillium, London, Academic Press, 1979, p. 5.

14 Ibid.

${ }^{15}$ R. Hare, 'New light on the history of penicillin', Med. Hist., 1982, 26: 1-24, p. 17.

16 D. Geraint James, 1984, personal communication.

17 Z. Cope. The history of St Mary's Medical School, London, Heinemann, 1974, p. 120.

18 A. Fleming. 'The uses and limitations of penicillin', Trans. Med. Soc. Lond., 1945, 64: 145.

${ }^{19}$ Hare, op. cit., note 15 above, p. 23.

20 Ibid., p. 20.

${ }^{21}$ M. Wainwright and H. T. Swan, 'C. G. Paine and the earliest surviving clinical records of penicillin therapy’, Med. Hist., 1986, 30: 42-56.

22 Hobson and Galloway, op. cit., note 4 above, pp. 61-67. 


\section{Wainwright}

possibility of using the products of certain micro-organisms against pathogenic bacteria. $^{23,24}$

\section{The Re-emergence of Crude Penicillin}

It would be reasonable to conclude that the successful purification of penicillin, followed by the demonstration of its remarkable therapeutic powers, would have brought the story of crude penicillin to a fitting end. In reality, it only rekindled interest in Fleming's mould juice. This was because there was not enough of the purified product available in the early 1940s for widespread use in hospitals, let alone for use by general practitioners. Since the large-scale purification of penicillin was a specialized and complex procedure, workers turned instead to crude penicillin, hoping that it would be a useful stop-gap until the purified product became more widely available. Consequently, the struggle to purify penicillin ironically led to a renewed interest in the use of crude filtrates of Penicillium notatum.

A. M. Fisher, of Johns Hopkins Hospital in Baltimore, using Fleming's original strain of $P$. notatum, was one of the first workers to re-investigate the therapeutic potential of crude penicillin, publishing his studies in $1943 .{ }^{25}$ An earlier study of Bordley and co-workers ${ }^{26}$ had appeared in 1942, but only a small section of the paper was devoted to crude penicillin. The most important difference between the work of Fleming and Fisher was that the latter grew the fungus on Czapek-Dox medium, rather than on bacteriological broth. Czapek-Dox is a synthetic medium containing glucose or sucrose as the carbon source, and inorganic sources of nitrogen and phosphorus. As it contains no proteins, it is less likely than bacteriological broth to cause toxic reactions when used directly on patients. Fisher grew $P$. notatum in this medium at $22-25^{\circ} \mathrm{C}$, filtered off the mycelium, then adjusted the filtrate to $\mathrm{pH} 6.5$ and stored the resultant solution in a freezer at $-30^{\circ} \mathrm{C}$. The strength of this crude penicillin was then tested at intervals using a titre method.

Fisher commented at some length on the instability of crude penicillin, regarding it as a serious handicap to its use. His findings on this matter are historically important since they confirm the view of both Fleming and Paine on the instability of crude penicillin, and help to explain why the crude filtrates were less successful on patients than these pioneering workers had hoped. ${ }^{27}$ Fisher showed that crude penicillin was non-toxic and non-irritating to tissues of test animals. He measured the potency of his crude filtrates as the equivalent of twenty to forty Oxford Units, rising to fifty units when concentrated by freezing and thawing. This compares with Fleming's cultures, which contained only one or two units. In this preliminary paper, Fisher gave a number of examples of the successful therapeutic use of crude penicillin, but also reported

\footnotetext{
${ }^{23}$ S. A. Waksman, The antibiotic era, Tokyo, Waksman Foundation, 1975.

${ }^{24}$ R. J. Dubos, 'Studies on a bacteriocidal agent extracted from a soil bacillus', J. exper. Med., 1939, 70: $1-10$.

${ }^{25}$ A. M. Fisher, 'The antibacterial properties of crude penicillin', Bull. Johns Hopk. Hosp., 1943, 73: 343-378.

${ }^{26}$ J. E. Bordley, S. J. Crowe, D. A. Dolowitz, and K. L. Pickrell, 'The local use of sulfonamides, gramicidin (tyrothricin) and penicillin in otolaryngology', Ann. Otol. Rhin. Laryng. St Louis, 1942, 57: 936-944.

${ }^{27}$ Wainwright and Swan, op. cit., note 21 above.
} 
complete failures-echoes here of the experiences of both Fleming and Paine. Fisher also stated that crude penicillin was used unsuccessfully on nine patients suffering from chronic leg ulcers. These results were particularly interesting, as it is likely that A. Dickson Wright had earlier used Fleming's filtrates on these infections, since he was a noted authority on indolent ulcers of the leg. ${ }^{28}$ The following statement by Fisher also helps to account for the lack of spectacular therapeutic success achieved by Fleming and Dickson Wright with crude penicillin:

\begin{abstract}
Most of the patients showed some improvement clinically but no more than one might expect from the increase in frequency of the dressings .... This type of therapy would not be expected to be effective in such conditions, because the penicillin loses its effect in the course of a day or so and then may serve as a culture medium for any bacteria that are left, and it is useless in the presence of proteus or pyocyaneus. The only way in which we could hope for successful treatment of chronic leg ulcers with crude penicillin would be to have the patients in bed and the material sprayed over the ulcer every two to three hours.
\end{abstract}

It seems likely, therefore, that Fleming, in asking his colleague Dickson Wright to help him with the clinical studies on penicillin, inadvertently chose one of the worst infections possible on which to demonstrate crude penicillin's therapeutic effectiveness. In a later study, Fisher obtained crude penicillin titres of 25-100 units and reported treatment of ninety-five cases of a variety of local infections. The results were described as good in sixty-three per cent of these cases, indefinite in twenty-four per cent, and poor in only thirteen per cent. ${ }^{29}$

1944 was a particularly productive year for papers on the therapeutic use of crude penicillin. Dunayer and his co-workers, for example, used crude penicillin on patients whose diseases failed to respond to other agents. ${ }^{30}$ One of their patients was suffering from a bad haemolytic $S$. aureus infection of the nose, throat, and larynxsulphadiazine and steam treatment were given without success, followed by sulphatriazole. Finally, crude penicillin was applied as nose and throat drops four times a day. The patient improved, and penicillin treatment was discontinued after the third day. Unfortunately, the tracheotomy became infected with $S$. aureus, but a further nine days' treatment with crude penicillin led to complete healing, leaving a smooth scar. In another example, a six-year-old boy was admitted to the hospital diphtheria service with a five-day history of illness. He had a temperature of $104.8^{\circ} \mathrm{F}$ and was comatose. Heavy membrane tonsilitis was diagnosed, with cervical adenitis and a "bull neck" suggestive of diphtheria. Bacterial examination revealed $S$. aureus. Sulphadiazine was administered without success, and then crude penicillin was applied every three hours for three days and then four times a day thereafter for a further three days. At the end of ten days' treatment, a complete clinical recovery was achieved. In an addendum, the use of crude penicillin on a critically ill eight-year-old girl with a temperature of $106^{\circ} \mathrm{F}$ caused by a streptococcal infection of the left hand was also reported. In this case, sulphadiazine and crude penicillin were applied as an inoculated

${ }^{28}$ A. Dickson Wright, 'The treatment of indolent ulcer of the leg', Trans. Med. Soc. Lond., 1931, 53: 237-251.

${ }^{29} \mathrm{~A}$. M. Fisher, 'The therapeutic value of penicillin applied locally based on experience with the crude material in a variety of infections', Bull. Johns Hopk. Hosp., 1945, 76: 134-153.

${ }^{30} \mathrm{C}$. Dunayer, L. Buxbaum, and $\mathrm{H}$. Knobloch, 'Crude penicillin: its preparation and clinical use externally', Ann. Surg., 1944, 119: 791-795. 


\section{Wainwright}

gauze dressing which was kept moist with filtrate. After ten days' treatment, the lesions were healed with very little scarring. A younger sister of the patient was admitted to the hospital with similar symptoms, but she received only sulphadiazine. In her case, surgery was necessary and the wound was still draining some weeks after the operation.

The Penicillium-inoculated gauze dressing used in this last example was pioneered by Robinson and Wallace. ${ }^{31}$ Hobson and Galloway ${ }^{32}$ also reported the use of inoculated gauze dressings on ten cases (burns, lacerations, ulcers, and infected wounds), preventing infection in three cases and being helpful in the control of seven. However, probably the best account of the use of gauze inoculated with $P$. notatum was given by Myers et al. ${ }^{33}$ They described how circles of absorbent gauze were cut out and placed into Petri dishes and sterilized for an hour at $400^{\circ} \mathrm{F}$. Culture medium was then poured over the gauze discs and inoculated with $P$. notatum. After incubation at $25^{\circ} \mathrm{C}$, penicillin secreted by the mould was deposited on the underside of the gauze, reaching a maximum concentration after twelve days. The inoculated gauzes were checked for the presence of contaminants, and then applied to wounds and held in place by adhesive tape or bandages. Several cases of uterine cervicitis were also treated by these workers, using mould-inoculated gauzes held inside the vagina with a vaginal tampon. Of forty-seven cases of a variety of infections treated with crude penicillin by Myers $e t$ al., twenty-five were healed and thirteen showed some improvement. (The fact that fourteen out of thirty-three cases of leg ulcers responded well to crude penicillin treatment is of particular interest regarding what has been said above about the Fleming-Dickson Wright collaboration.) Despite achieving considerable success with crude penicillin, Myers and co-workers concluded that it was much more difficult to prepare than was generally recognized, and they suggested that rather than prepare the crude variety themselves, civilian physicians should wait for a more plentiful supply of the purified product to become available.

Despite an easing in the supply of purified penicillin, reports on crude penicillin continued to appear during 1945. One series of particularly interesting papers was published in the Hawaiian Planters' Record, the journal of the Hawaiian Sugar Planters' Association. Although usually devoted exclusively to papers on sugar cane production, this journal published in 1945 a series of papers on crude penicillin, giving the somewhat tenuous reason that its production would benefit workers in the sugar cane industry. ${ }^{34}$ Three papers on crude penicillin appeared together. The first dealt with studies on the production of the crude product (Carpenter et al.), ${ }^{35}$ the second concentrated on clinical studies (Larsen), ${ }^{36}$ while the third was devoted to a preliminary report on the production and use of crude penicillin in a naval dispensary (Agmar). ${ }^{37}$ The first paper covered familiar ground relating to the growth of $P$.

${ }^{31}$ G. H. Robinson and J. E. Wallace, 'Inoculated penicillin dressing', Science, 1943, 98: 329.

${ }^{32}$ Hobson and Galloway, op. cit., note 4 above.

${ }^{33}$ R. S. Myers, R. H. Aldrich, R. W. Howard, and R. A. Walsh, New Engl. J. Med., 1944, 231: 761-764.

${ }^{34}$ Anon. Editorial, Hawaiian Planters' Record, 1945, 49: 1.

${ }^{35}$ C. W. Carpenter, D. M. Weller, and J. P. Martin, 'Studies with Penicillium notatum Westling in Hawaii', ibid., pp. 1-24.

${ }^{36}$ N. P. Larsen, 'Clinical studies with crude penicillin', ibid., pp. 25-30.

${ }^{37}$ A. R. Agmar, 'A preliminary report on the production and use of crude penicillin solution in a naval dispensary', ibid., pp. 31-40. 
notatum, and techniques for optimizing the production of crude penicillin. An excellent description of the preparation of Penicillium-inoculated dressings was also given: these were in constant demand both by civilian and service physicians.

A number of service physicians and technicians had been supplied with Penicillium cultures, and instructed in their preparation and use, so that approximately one hundred physicians on Hawaii eventually used crude penicillin, with what was described as "outstanding success". The scale of production of crude penicillin on the island can be appreciated from the fact that Lieutenant Commander A. R. Agmar was preparing forty bottles every week, each containing four hundred inoculated dressings. ${ }^{37}$ The acknowledgement given at the end of the paper emphasizes the enthusiasm then current for crude penicillin: "It is believed that the project has contributed materially to labour turnout, and to relief of hospital congestion, and that it has benefited the health and morale of servicemen as well as civilians." The scale of production of crude penicillin on Hawaii can be further gauged from the fact that sufficient dressings and penicillin solution were produced to supply any naval depot or ship in the district, and that facilities were made available so that any interested medical staff could be readily trained in its production.

In the second paper of this series, Dr Nils Larsen detailed some clinical trials involving crude penicillin. He expressed considerable enthusiasm for its use, noting that if the organism was sensitive to crude penicillin, then the effects were dramatic. He also commented that crude penicillin filtrates were cheap and easy to make, simple to use, and readily transportable, and concluded with the following statement: "We feel now that a source of a rather scarce and potent drug is readily available to anyone who may be willing to produce it wherever he may be". Such enthusiasm was not universal, Johnson, ${ }^{38}$ for example, commenting on the use of crude penicillin against impetigo contagiosa and sycosis vulgaris, cautioned that contamination would render the cultures useless or possibly dangerous. He also pointed out that the repeated use of dilute penicillin solutions might encourage the development of penicillin-resistant bacteria. ${ }^{38}$ Such fears were amplified in 1943 in a letter to Science by the eminent mycologists, Raper and Coghill. ${ }^{39}$

A third means of administering crude penicillin topically that received relatively little attention was its incorporation into agar to form so-called pen-agar. ${ }^{40.41}$ This jelly was applied to superficial infections by smearing it heavily on lint and then holding the lint by a bandage backed by cellophane. The jelly apparently turned into an emulsion, which, when pressed, became packed deep into wound cavities. It was left in place for between twenty-four and forty-eight hours. Results were reported as being similar to those reported by Alston ${ }^{42}$ using crude penicillin in liquid form, so no particular increase in curative properties seems to have been achieved by the use of pen-agar. Pen-agar was manufactured by P. C. Cahill in Dublin from $1944 ;{ }^{43}$ the term was also later used to describe a similar product containing purified penicillin. ${ }^{44}$

\footnotetext{
${ }^{38}$ H. M. Johnson, 'Penicillin therapy of impetigo contagiosa and allied diseases: Use of penicillin inoculated dressing', Archiv. Derm. Syphilol. Chicago, 1944, 50: 1-5.

${ }^{39}$ K. B. Raper and R. D. Coghill, 'Home-made penicillin', J. Amer. Med. Assoc., 1943, $123: 1135$.

40 O. Roberts and D. Murphy, 'Penicillin agar', Irish J. med. Sci., 1944, 225-230.

${ }^{41}$ O. Roberts, 'Agar for local penicillin therapy', Lancet, 1945, ii: 383

42 J. M. Alston, 'Use of crude Penicillium filtrate for local treatment', Br. med. J., 1944, i: 645-656.
} 


\section{Wainwright}

The successful reports on the use of crude penicillin naturally encouraged workers to try and improve yields and storage times, particularly in relation to the possibility of producing it in well-equipped hospital laboratories. Sandercroft, for example, provided a description to be followed for the routine production of crude penicillin on Czapek-Dox medium. ${ }^{45}$ After filter sterilization, the product could be kept for up to a month at $4^{\circ} \mathrm{C}$, and even as long as three weeks at room temperature. Other workers, however, recommended that the crude filtrates should be frozen. Tsun Tung, ${ }^{46}$ for example, suggested that the crude filtrates should be first adjusted to $\mathrm{pH} 6.0$, evaporated under reduced pressure, and then finally placed in celluloid tubes and frozen at $-76^{\circ} \mathrm{C}$. After such treatment, the potency of the crude penicillin was maintained for a month, but was reduced to half that of the original after two months, when it then remained stable for a further three to five months.

\section{Crude Penicillin given by Injection}

In 1943 , Robinson ${ }^{47}$ performed the protection tests on laboratory animals with crude penicillin that Fleming and others had failed to do in the early 1930s. Robinson showed that crude penicillin was toxic to mice when given intravenously in single doses of $0.5,1.0,1.5$, and 2 grams per kilogramme. The toxic dose was, however, sixty-four times the effective dose. Without doubt the most remarkable studies on the therapeutic potential of crude penicillin were made by D. F. Gray and J. V. Duhig, respectively lecturer in bacteriology and professor of pathology at the University of Queensland. ${ }^{48}$ They prepared crude penicillin using a defined medium containing glucose, and applied it locally to infections by soaking it in gauze. Using this familiar approach, they cured cases of cellulitis, osteomyelitis, abscesses, impetigo, carbuncles, and miscellaneous infections - in particular, those of burns caused by Staphylococcus aureus. They then went on to inject sterile, crude penicillin intravenously into terminally-ill patients, often with striking success. In one example, a baby boy was suffering from appendicitis and peritonitis, the cause of which was unknown. The appendix was gangrenous and perforated, and free pus was present. Sulphonilamide had been used without success, and the boy's condition deteriorated until it became desperate. Crude penicillin was given by intravenous drip in doses of $300 \mathrm{mls}$ each day for four days. There was an immediate improvement in his condition, and he eventually recovered. Similar successes following the injection of crude penicillin were achieved against septic embolic pneumonia with suppurative cellulitis of the buttock, osteomylitis of the pubis and ischium with sinus into the bladder, and staphylococcal septicaemia. There were some failures, however, mainly in cases where the condition of the patient had deteriorated to such an extent that only purified penicillin might have

\footnotetext{
43 Anon., Lancet, 1944, ii: 383.

44 R. B. Coles, A. N. Barker, E. A. Robertson, and S. T. Cowan, 'Agar for local penicillin therapy", ibid., 1945 , i: $720-721$.

45 R. M. Sandercroft, 'The production and assay of crude penicillin filtrate in the hospital laboratory'. Monogr. Bull. Inst. Med. Lah. Technicians, 1944: 56-58.

46 Tsun Tung, 'Concentration and preservation of crude penicillin'. Proc. Soc. Ex.yer. Biol. Med., 1943, 54: $103-105$.

${ }^{47}$ H. J. Robinson, 'Toxicity and efficacy of penicillin', J. Pharm. exper. Therap., 1943, 77: 7079.

48 D. F. Gray and J. V. Duhig. 'Crude penicillin therapy', Med. J. Australia. 1945: 60 63.
} 
helped. The concluding statement of Gray and Duhig placed them into that large group of workers who were enthusiastic about the merits of crude penicillin. "Although pure penicillin is becoming available slowly for civilian use, it is believed that crude penicillin will continue to play an important role in the treatment of local infections caused by Gram-positive pyogenic bacteria, for it can be produced in any hospital laboratory by a skilled technician at negligible cost and with a minimum of labour."

The examples mentioned above clearly show that crude penicillin filtrates could prove remarkably successful against a wide range of bacterial infections. If correctly used, they could therefore have acted as an important "stop-gap" until supplies of the purified product became more generally available. However, the use of crude penicillin soon became subject to a certain amount of controversy. Fears were rightly expressed that the uncontrolled production and use of such crude material might prove hazardous, thereby ruining the reputation of the purified product. In a letter to the British Medical Journal, ${ }^{49}$ a general practitioner asked how he could obtain and grow a culture of $P$. notatum. He proposed to inject the filtrate into the vagina of a six-year-old girl who was suffering from gonorrhoea and was not responding to other treatment. He asked "Why should not this culture in liquid be used as a local application until the supply of penicillin is abundant?" A good question, met by a somewhat off-putting reply from the editor: "Despite recent claims which have been made for the possibilities of home-made penicillin, the pitfalls involved are so numerous that it cannot be recognised for any serious therapeutic undertaking such as in the case described." The editor was being strangely cautious, since his own journal and the Lancet would eventually publish reputable studies showing the effectiveness of crude penicillin. ${ }^{50.51}$ A more balanced response would have been to discourage the general practitioner from attempting to produce crude penicillin, while suggesting that he try and enlist the help of a local hospital laboratory.

A reply along these lines was given in Parliament (28 January 1944) by the then Minister of Health, Mr Willink. ${ }^{52}$ "I am aware that some research workers have published notes on so-called home made penicillin. I appreciate the importance of this work but I am advised that the small scale production of this substance is attended by special difficulties of purification and standardisation." That this balanced view was not widely proffered can be seen from an earlier quotation from The Times. ${ }^{53}$ "A suggestion has been made as a result of some work in America and somewhat irresponsibly repeated in this country that crude penicillin grown as a gauze used for dressing wounds would solve the problem of supply [of penicillin]. There are dangers in this method, however, and the War Office Report is emphatic that penicillin which has not been properly tested should not be used in any circumstances."

Questions on crude penicillin continued to be asked in Parliament during 1944. On 18 May, for example, Mr Hewlet asked the Minister of Supply whether he was in the position to report on the possibility of producing penicillin in any bacteriological

${ }^{49}$ Letter to Br. med. J., 1944, ii: 423.

50 Alston, op. cit., note 42 above.

${ }^{51}$ M. A. Cole, 'Penicillin in sycosis barbae', Lancet, 1945, i: 543--544.

52 The Times, 18 February 1944, p. 8.

53 Ibid., 14 December 1943, p. 5. 


\section{Wainwright}

laboratory with a well-trained staff. ${ }^{\supset 4}$ The Joint Parliamentary Secretary for Supply replied: "Small quantities of penicillin in its crude filtrate form can be produced by any bacteriological laboratory. The penicillin could be used for treatment in certain cases under special medical supervision. Such laboratories would not be able to make a significant amount of penicillin for general distribution." This is again a balanced response to the question of the use and production of crude penicillin. It neglects, however, the possibility that regional centres for the preparation of crude penicillin could have been set up on the Hawaiian model. Members of Parliament came under increasing pressure from constituents to press for a better supply of penicillin. On 19 October 1944, for example, Mr G. Griffiths ${ }^{55}$ asked the Minister of Health if he was aware that some workers were making penicillin in a laboratory in the West Riding. The questioner is probably referring to the work done in Bradford at the Royal Infirmary by $\mathbf{M}$. A. Cooke ${ }^{56}$ who used sprays of crude penicillin to cure sycosis barbae; the disease against which Paine and Hallam had earlier had no success. ${ }^{21}$

Florey himself appears to have been concerned about the increasing interest in the clinical use of crude penicillin. ${ }^{57}$ In particular, he seems to have regarded Pulvertaft's use of crude penicillin on wounded Allied soldiers in North Africa ${ }^{58}$ as an "unnecessary and retrograde step", a criticism which appears to have curtailed Pulvertaft's work on the crude product. Florey was obviously determined here to protect penicillin's reputation against the misuse of Fleming's mould juice.

All forms of penicillin finally came under the control of the Therapeutic Substances Act of $1944 .{ }^{59}$ This made any commercial form of penicillin conform to prescribed standards of quality, potency, and purity. Crude filtrates were specified in the Act, together with dried crude filtrates, the sodium and calcium salts, and other salt preparations. If offered for sale, the crude filtrate had to contain not less than ten units of penicillin per $\mathrm{ml}$. In addition, any substance advertised as containing live Penicillium ("Viviclin") was to be free of viruses, bacteria, or any organisms other than those which it was meant to contain, and its administration must be free from danger to patients. These regulations excluded penicillin that was not meant for sale, such as that produced in hospital laboratories. It remains debatable whether official encouragement should have been given to the production and use of crude penicillin in the early 1940s. Although there were obvious dangers involved in its use, numerous studies showed that crude penicillin could have helped alleviate suffering and may even have saved lives. It might have proved particularly beneficial for civilian use, since most of the purified penicillin then available was saved for battle casualties. The use of crude pencillin achieved some official recognition in the UK by being mentioned in an Act of Parliament. In the end, however, it came too late, as sufficient supplies of the purified product soon became more widely available.

\section{ACKNOWLEDGEMENT}

Thanks are due to Dr D. Geraint James for correspondence concerning Mr A. Dickson Wright.

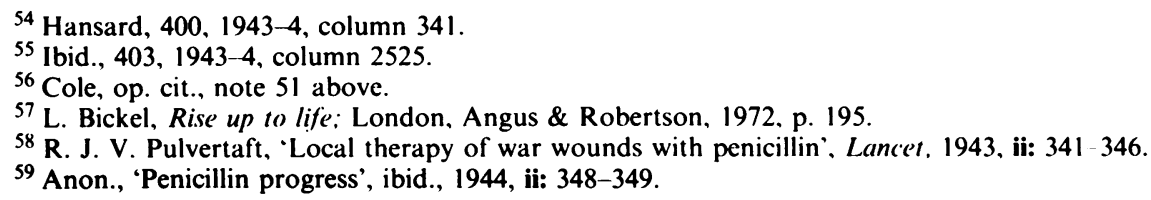

